\title{
Application of Neutron Moisture-Gauge in the Steel Industry*
}

\author{
By Kazuo MIYAGAWA, ${ }^{* *}$ Isamu MISHIMA, ,** Tadao TAKEDA, ${ }^{* * *}$ and Yoshinori TANABIKI ${ }^{* * *}$
}

\section{Synopsis}

A series of fundamental experiments and on-line tests were conducted for the utilization of neutron moisture gauge in steel industry $A$ method of automatic moisture control for the sinter raw mixture as well as an automatic moisture control method for the blast furnace coke were accomplished.

Here reported are the principle and the features of this neutron moisture gauge, the results of the fundamental experiments, and the condition of control together with some problems encountered during the on-line tests.

\section{Introduction}

The neutron moisture gauge, one of the radioactive isotope applications for measurement, permits very simple and quick measurement of the moisture contained in various materials with the moderation of neutrons by hydrogen. For this reason the gauge rapidly comes into wide use in various fields, such as steelmaking, civil engineering, paper making, glass and other industries.

The neutron moisture gauge was originally utilized in ground surveys, concrete moisture measurement, following the publication of results obtained in soil moisture measurement studies in the early 1950's. The commercial gauge for civil engineering was marketed by the Nuclear-Chicago Corporation around 1958, followed by similar gauges in Japan.

The gauges in those days were of the portable type with a detector and a counting circuit. The moisture content was calculated from a set of calibrating curves prepared in advance by measuring counts for a certain time.

The authors interested in the advantage of the neutron moisture gauge, started various studies from 1958 aiming at the application of this instrument to various process controls in the steel industry. Specifically a series of fundamental experiments and on-line tests were conducted on the utilization of the neutron moisture gauge for the moisture measurement of sinter raw materials and of blast furnace lump coke, a method of automatic control for the moisture content of sinter raw mixture and a method of automatic correcting and weighing the moisture content of blast furnace lump coke were developed.

The characteristics of the neutron moisture gauge and examples of their applications in the steel industry will be discussed in the subsequent sections.

\section{Principles, Construction, and Characteristics of the Neutron Moisture Gauge}

\section{Principles of Measurement}

When the $\alpha$-particles, emitted from americium or radium, and its daughter nuclei impinge upon beryllium nuclei, fast neutron bearing high energy will be released by ${ }^{9} \mathrm{Be}(\alpha, \mathrm{n}){ }^{12} \mathrm{C}$. These fast neutrons during their passage through a material would repeat mainly an elastic scattering with the nuclei of the material until the energy of thermal neutrons becomes the same degree of energy as that of thermal movement of material atom. While this process of losing energy is termed as moderation, this slow down power varies depending on the material atoms, as shown in Table 1. Because hydrogen has an overwhelmingly great slow down power, the density of thermal neutrons produced by the moderation of fast neutrons can safely be said to be determined solely by the amount of hydrogen.

The density of thermal neutrons convertible to the amount of hydrogen and the moisture content in the sample can be measured by the neutron moisture gauge, consisting of neutron source and a detector sensitive only to thermal neutrons.

Table 1. Nuclear properties of elements for neutron

\begin{tabular}{l|c|c|c|c}
\multicolumn{1}{c|}{$\begin{array}{c}\text { Element } \\
\text { (Mass } \\
\text { number) }\end{array}$} & $\begin{array}{c}\text { Absorption } \\
\text { cross } \\
\text { section, } \\
\text { barn }\end{array}$ & $\begin{array}{c}\text { Scattering } \\
\text { cross } \\
\text { section, } \\
\sigma_{s}, \text { barn }\end{array}$ & $\begin{array}{c}\text { Average } \\
\text { logarithmic } \\
\text { energy } \\
\text { decrement } \\
\text { per collision } \\
\xi\end{array}$ & $\begin{array}{c}\text { Slow down } \\
\text { power per } \\
\text { atom } \\
\sigma_{s} \times \xi\end{array}$ \\
\hline H (1) & 0.33 & 20 & 1.000 & 20 \\
C (12) & 0.003 & 4.6 & 0.158 & 0.727 \\
N (14) & 1.88 & 9.3 & 0.136 & 1.265 \\
O (16) & 0.0002 & 3.8 & 0.120 & 0.456 \\
S (32) & 0.49 & 1.2 & 0.061 & 0.073 \\
Cl (35) & 32.6 & 4.4 & 0.056 & 0.246 \\
Mn (55) & 13.2 & 4.0 & 0.036 & 0.014 \\
Fe (56) & 2.53 & 12.0 & 0.035 & 0.420 \\
Ni (59) & 4.6 & 17.0 & 0.032 & 0.544 \\
\hline
\end{tabular}

\section{Construction}

The neutron moisture gauge is composed of a fast neutron source, a thermal neutron detector, and a pre-amplifier as shown in Fig. 1.

As the fast neutron source, either ${ }^{241} \mathrm{Am}-\mathrm{Be}$ or ${ }^{226} \mathrm{Ra}-\mathrm{Be}$ is used, the former being rated at $300 \mathrm{mC}_{\mathrm{i}}$ (millicurie) and the latter at $10-20 \mathrm{mC}_{\mathrm{i}}$. Since

\footnotetext{
* Originally published in Fuji Technical Reports, 16 (1967), 246 in Japanese. Manuscript received October 18, 1968.

** Senior Research Engineer, Research Laboratory, Hirohata Works, Fuji Iron \& Steel Co., Ltd., Hirohata-ku, Himeji 671-11.

*** Technical Department, Hirohata Works, Fuji Iron \& Steel Co., Ltd., Hirohata-ku, Himeji 671-11.
} 
americium emits a few gamma rays, whereas radium involves intensive gamma rays, $\mathrm{Am}-\mathrm{Be}$ is used recently so that the operator may be better protected from the effect of radiation. The half-life time would raise no practical problem, because it is not less than $1660 \mathrm{yr}$ for radium and $460 \mathrm{yr}$ for americium.

As the thermal neutron detector, $\mathrm{a} \mathrm{BF}_{3}$ counter is used. Being a sort of proportional counter with sealed $\mathrm{BF}_{3}$ gas, the ionization current pulse of the ionized $\mathrm{BF}_{3}$ gas by the rays arising from nuclear reaction of ${ }^{10} \mathrm{~B}(\mathrm{n}, \alpha){ }^{7} \mathrm{Li}$ can be measured.

The detector of the neutron moisture gauge is available in two types, (A) the insertion type (Fig. 1.) and (B) the surface type (Fig. 2), which are used, respectively, in accordance with the different purposes intended. Figure 3 shows the results obtained by the insertion and surface types for the measurement of the moisture content of the same sinter raw mixture.

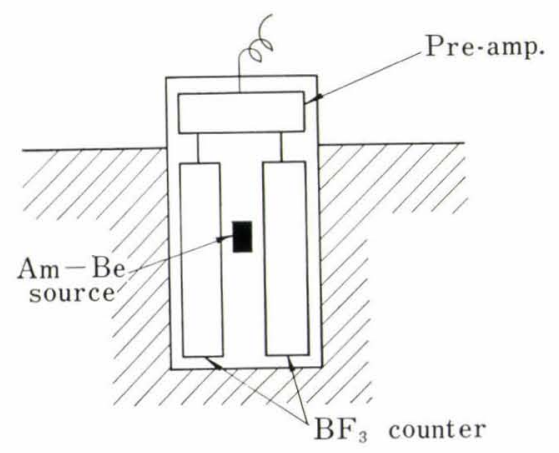

Fig. 1. Insertion type detecting head

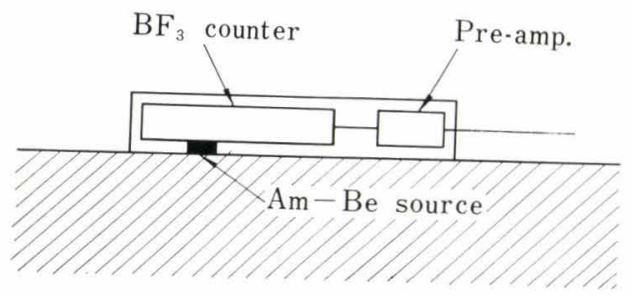

Fig. 2. Surface type detecting head

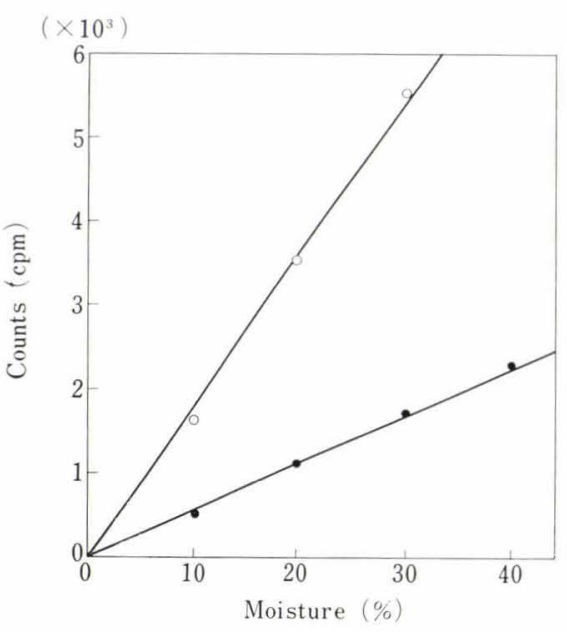

Fig. 3. Comparison of insertion type and surface type of detecting head on the sinter raw mixture

\section{Characteristics}

\section{Advantages of the Neutron Moisture Gauge}

The neutron moisture gauge has the following advantages :

(1) It permits moisture measurement in the relatively short time of 1 to $2 \mathrm{~min}$, and does not require sampling.

(2) It being radioactivity measurement, the output proportional to moisture content is obtainable in the form of an electric signal by connecting the instrument to a rate meter. Therefore, continuous on-line measurement is possible for automatic control.

(3) Because the density of thermal neutron in the relatively great volume is measured, the result may well be considered representative value of the whole.

However, since the moisture content is not directly measured by the neutron moisture gauge, full precaution must be paid to its characteristics stated below.

\section{Effective Volume}

Neutrons emitted from the neutron moisture gauge are moderated as they repeat a scattering and absorbing movement with the material elements, and only those are counted which are incident upon the $\mathrm{BF}_{3}$ counter. And as the sample is progressively increased around the gauge probe, the moisture gauge output approaches a constant value beyond a certain volume and finally reaches saturation. The thickness and volume of the material layer for the constant output are termed effective thickness and effective volume, respectively.

Therefore, it is necessary that the sample amount is greater than the effective volume. In selecting the site for detector installation, moreover, care must be taken so that the sample may not be less than the effective volume. It also must be noted that this effective volume varies in accordance with the type of material to be treated.

\section{Density}

The output of the neutron moisture gauge is proportional to the hydrogen amount per unit weight of sample, and variation of the sample density corresponds to variation of the hydrogen amount per unit weight of the sample, so that correct calculation of the moisture content is impossible unless the sample is measured under the same density. For samples with wide density variations, the density correction is necessary by a gamma-ray density gauge or the like.

\section{Moisture Segregation}

The gauge output is determined by the number of thermal neutrons incident upon the $\mathrm{BF}_{3}$ tube. The fast neutron flux is the denser, the nearer it is to the neutron source, so that the hydrogen atoms of the nearest to the source will determine the number of thermal neutrons. In case there is much moisture segregation in the sample, the distribution of thermal neutrons in the effective volume would vary and cause errors. Consequently sticking dirt adhesion, hanging, etc., near the detector would thereby lead to great errors, and particular care in respect to them must be taken when using the instrument. 
In the sample containing such elements as fluorine, boron, chlorine, and iron, which have a large slowdown power, the gauge output would decline apparently, so that caution is necessary.

Moreover, although it is a matter of course, attention must be paid to the composition of hydrogen containing substance, or organic matter, crystalled water, etc.

\section{Necessity and Fundamental Tests of Moisture Gauge}

1. Necessity of Moisture Gauge at Sinter Plants and Blast Furnaces

\section{Sinter Raw Mixture}

Sintering is an operation in which fine coke is mixed with as many as ten odd varieties of fine ore. The sinter raw mixture is made properly permeable by addition of moisture during the mixing process and then charged into a sintering machine, where the surface of the mixture is ignited by a gas burner and air is exhausted through an exhaustor on the other side, to sinter the fine ore to have properties suitable for blast furnace.

Figure 4 shows the results of sintering affected by changing the moisture content. From these results, sintering productivity varies greatly with the moisture content of sinter raw material, hence it is very important for sintering operations to keep the moisture content at an suitable value.

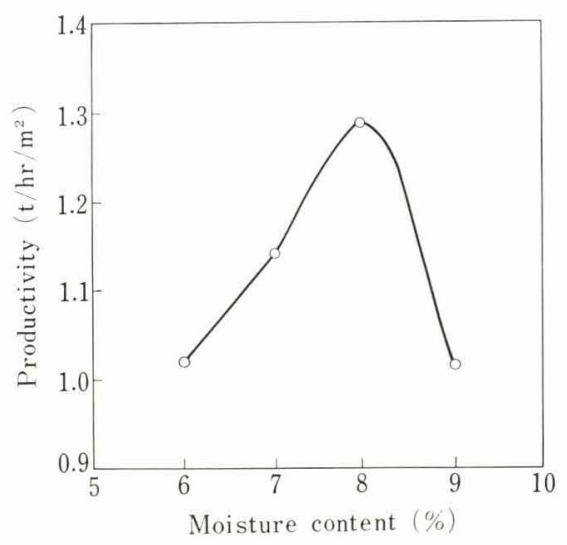

Fig. 4. The effect of moisture content of material to productivity of sinter

Previously, samples were taken at regular intervals of time and the moisture of the sinter raw mixture was measured by the so-called drying method. In actual work, the sinter raw mixture was grasped by the hand and the moisture content was judged by an operation which depended entirely on the workman's flair.

For this reason, various methods for rapid measurement of the moisture content of sinter raw mixture have been under study, including the drying method by ultra-red rays and the method which uses calcium carbide.

On the other hand, sintering plants in recent years have become increasingly large in size. All of them are using the DL type of sintering machines which are operated on a continuous production system, and re- cently large-sized machines with a daily capacity of 7000 t have come into operation.

To cope with this situation, a new method, which would detect such moisture content continuously and rapidly, has long been waited for. The conventional method has been proved to take too long time to detect it, and cannot follow the hourly changing moisture since continuous measurement was impossible and additional personnel was necessary for such measurement.

\section{Blast Furnace Goke}

In the blast furnace operation, where sinter, iron ore, limestone, and coke are charged from the furnace top and hot blast is blown into the furnace through the tuyeres to make pig iron, the coke is by far the most important factor. It holds very large ratio by volume compared with the iron ore and moreover, it serves as a retainer of porosity, a reducing agent, a fuel, etc.

In the actual work at the blast furnace, the stability of furnace working condition was disturbed by the inevitable great variation in the moisture content of the coke.

So far moisture of coke has been measured by the drying method. The small specific gravity of coke and its large grain size, 30 to $50 \mathrm{~mm}$, has induced large errors owing directly to the sampling and drying conditions. Moreover, the measurement required rather a long time. Therefore it has been almost impossible to utilize this method for the moisture control in the actual operation. The continuous measurement of moisture in coke is one of the most important measurements for the automatic operation of blast furnace.

\section{Fundamental Tests}

\section{Moisture Measurement of Sinter Raw Material}

Laboratory tests and on-line tests were carried out with the neutron moisture gauge, having an insertion type detector composed of $10 \mathrm{mCi}$ of $\mathrm{Ra}-\mathrm{Be}$ and four $\mathrm{BF}_{3}$ counters and a counting control unit composed of a high-voltage and low-voltage supply, a linear amplifier, a rate meter, and a recorder. Furthermore, a gammaray density gauge of ${ }^{60} \mathrm{Co} 100 \mathrm{mC}_{\mathrm{i}}$ was installed to carry out laboratory tests and on-line tests to make various studies on the suitable conditions of installation, measurement, etc., required for the introduction of neutron moisture gauge into the sintering process.

\section{(1) Effective Volume}

A wooden box $1000 \mathrm{~mm} \times 1000 \mathrm{~mm} \times 800 \mathrm{~mm}$ (depth) whose volume is variable was prepared, and the detector was placed in the box as illustrated in Fig. 5, to measure the gauge output while the amount of raw material around the detector varied. The measurement results are given in Fig. 5. These results revealed the need for a layer of more than $250 \mathrm{~mm}$ in thickness for the sinter raw mixture.

(2) Relationship between Counting Rate of the Gauge and Moisture Content

A life-size model of the surge hopper used in the Hirohata No. 1 D.L. sintering machine was built, and the model was charged with a sinter raw mixture with the adjusted moisture content to study the relation between gauge counting rate and raw material moisture content. 


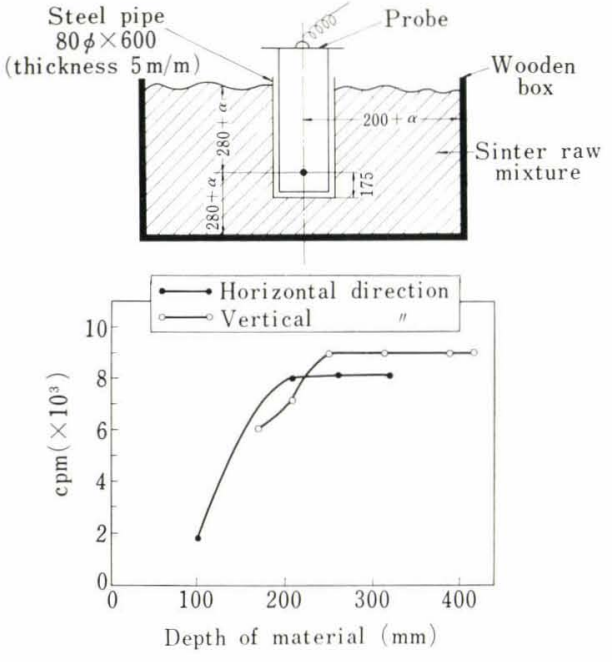

Fig. 5. Determination of effective volume

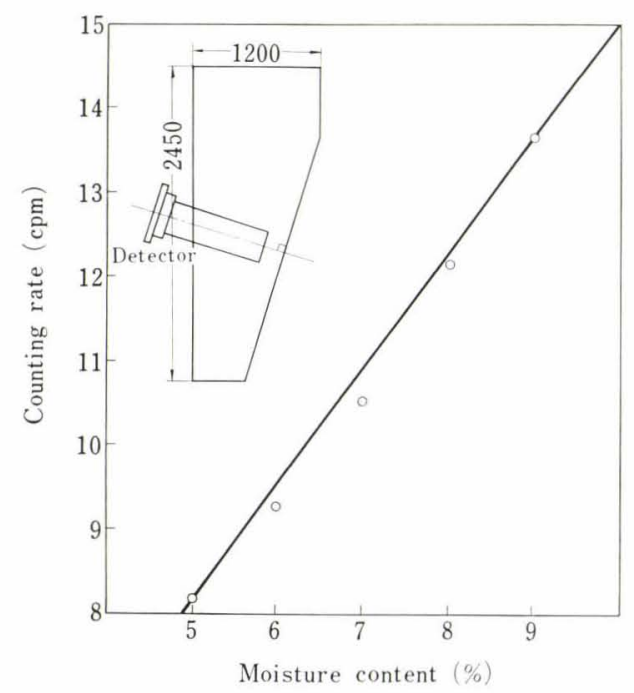

Fig. 6. Results of moisture measurement

The results are given in Fig. 6. These results disclosed the presence of a linear relation between variation of mixture moisture content and output of the gauge, and the possibility of measuring the moisture content of sinter raw mixture by the neutron moisture gauge.

\section{(3) On-line Tests}

A protective pipe was inserted at the midpoint of the bottom of the surge hopper of the Hirohata No. 1 D.L. sintering machine, and the detector was installed in the pipe to carry out on-line tests over a long period for the various studies on moisture gauge accuracy, instrument stability, use conditions, etc.

On the sintering machine, three pieces of the sinter raw mixture, $200 \mathrm{~g}$ each, were sampled per each run to measure their moisture content by the drying method and to seek the relationship between the measured values and the recorder output of the neutron moisture gauge. The results obtained are given in Fig. 7. These results revealed the presence of a linear correlation between the moisture content and guage output, but with rather much variation. This seems to be

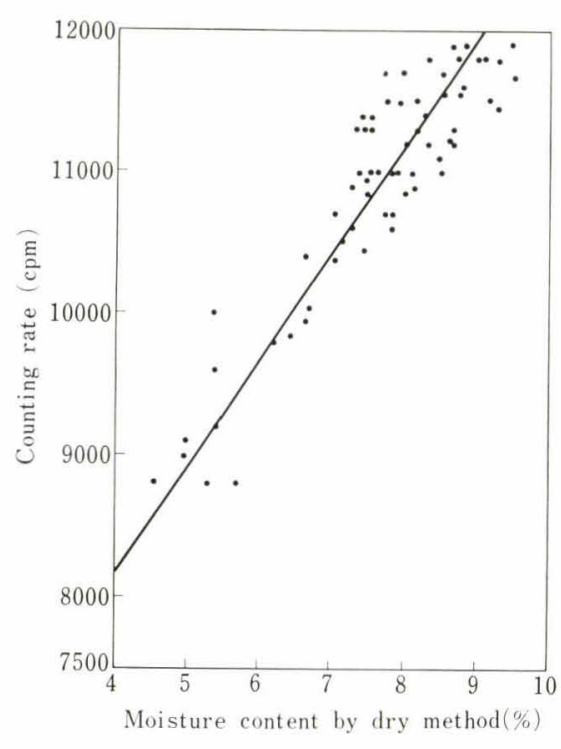

Fig. 7. Result of on-line test

due to the influence of raw material flow, density, etc., in the hopper.

The difficulties in the on-line tests are cloth fragments, wires, straw scraps, or the like caught in the protective pipe, causing the raw material to stick progressively. The protective pipe requires periodic replacement because its tip wears away. In the summer season, the pre-amplifier unit of the detector needs to be cooled because the temperature of the sinter raw mixture rises. It is necessary to keep the amount of raw mixture in the hopper constant. The response time of counting output was about $2 \mathrm{~min}$ with this test apparatus, and must be shortened in online tests.

(4) Relations of Raw Material Density to Moisture Content and Counting Output

Because the counting output is expected to vary with the raw material density, a gamma ray density gauge was installed on the surge hopper model used earlier. The sinter raw mixture was charged in five separate batches so as to provide uniform density, and thereby the relation of raw material density to moisture content and its counting output was observed. The results are given in Fig. 8. It turned out that, when the raw material density is constant, the relation of raw material density to moisture content and counting output shows a very favorable linearity, but when the raw material density varies, the counting output varies greatly even with the same moisture content. This result made it clear that, when the raw material density varies, a gamma ray density gauge must be installed in combination with other instruments.

\section{Moisture Measurement of Blast Furnace Coke}

By using the test apparatus employed for sinter raw mixture measurement, laboratory and on-line tests were carried out for the moisture measurement of blast furnace coke. From the result, it would be possible to measure the coke moisture by the neutron moisture gauge and feed the output into the scale for automatic moisture correction. 


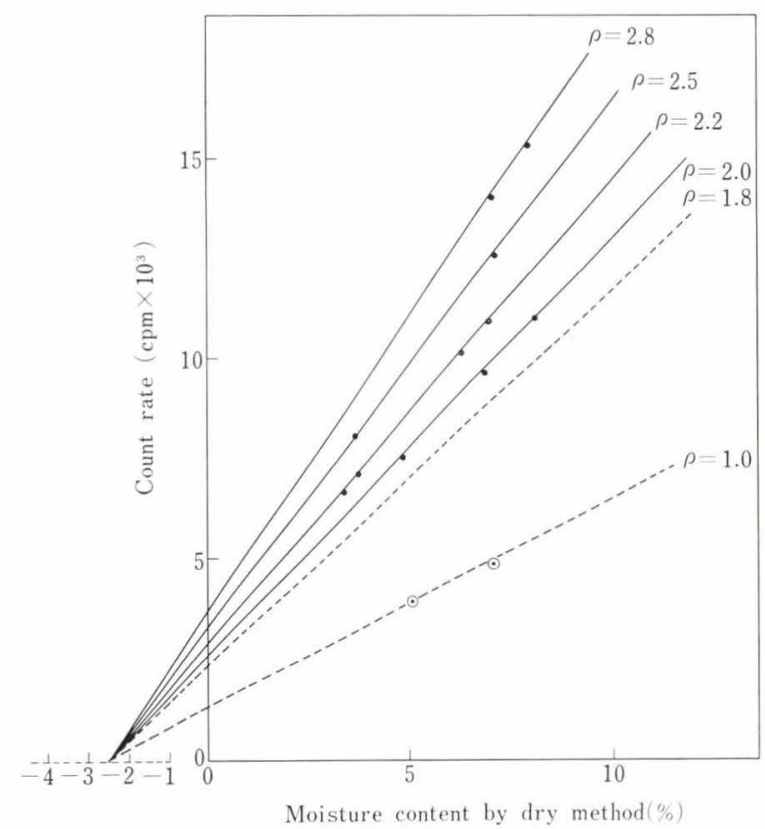

Fig. 8. The effect of density of material output of moisture meter

\section{(1) Effective Volume}

The detector was placed at the center of a wooden container measuring $1300 \mathrm{~mm} \times 1300 \mathrm{~mm} \times 900 \mathrm{~mm}$ (depth) and blast furnace coke was packed around the detector to determine the coke amount which would give the constant moisture counting rate. The results are given in Fig. 9. It has been found out that coke layer of $600 \mathrm{~mm}$ or more around the detector gives the constant counting rate.

(2) Relation between Counting Rate and Moisture Content

Shown in Fig. 10 are the test results obtained by varying the coke moisture content by using the wooden box employed for effective volume measurement. The results obtained disclosed that the counting rate has a linear relation to the moisture content, and that it is possible thereby to measure the coke moisture.

The moisture content measured by the drying method involves an error of plus or minus $0.25 \%$ due to sampling errors, caused by the coke size, and also to the manner of moisture addition. The $\Phi$ marks appearing in the chart denote statistic deviation of radiation, which can be reduced if the radiation source is enlarged and a larger time constant is used.

Furthermore, the test results obtained in respect to bedding ore, Indian ore, and sinter are given in Fig. 11 along with the results of coke and sinter raw mixture. For all these steel making raw materials, the moisture content bears a linear relation to the counting rate, and hence it is deemed possible to measure their moisture content by the neutron moisture gauge, although the inclination of the lines varies with various materials.

(3) Evaluation of Moisture Measurement by the Drying Method

Laboratory tests proved the possibility of coke moisture measurement by the neutron moisture gauge, but they have also proved the presence of considerable

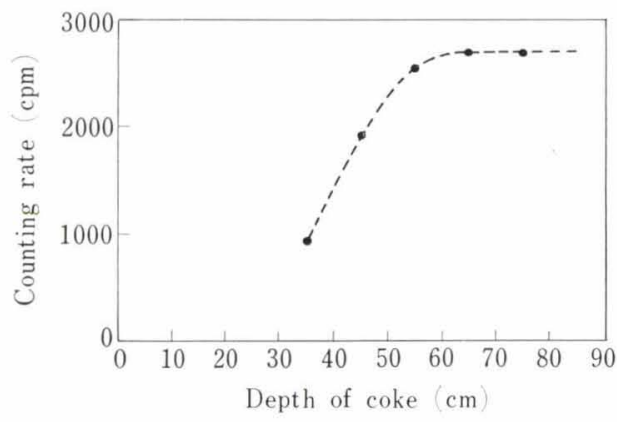

Fig. 9. Determination of effective volume

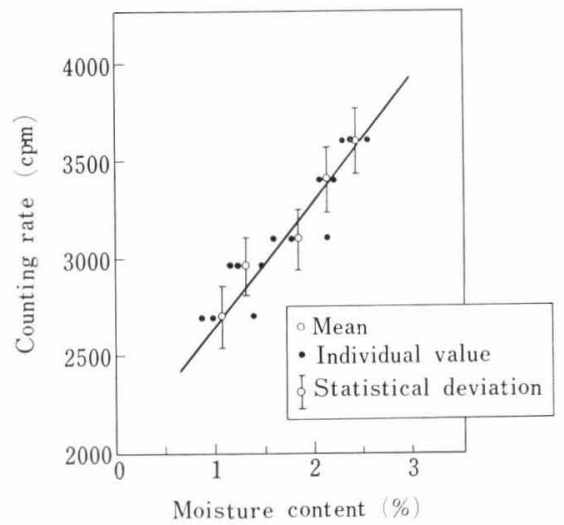

Fig. 10. Results of moisture measurement (off line test)

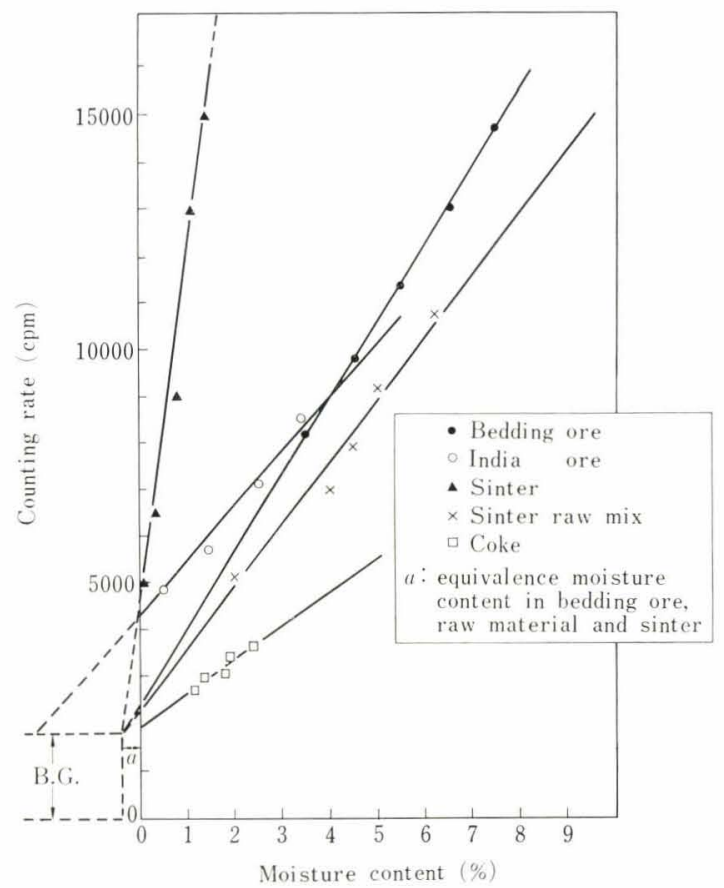

Fig. 11. Results of the moisture measurement by neutron moisture meter in various material

errors in the drying method used to measure the coke moisture content. Therefore, prior to the on-line test, evaluation of the drying method itself was carried out. Details of the tests were as follows :

Sample Amount : Tests carried out as to 1, 2, and $3 \mathrm{~kg}$ revealed the error to be the smaller, the greater the sample amount is, but in view of the drying 
oven's capacity and of the difficulty involved in sampling, the amount was set at 2 to $3 \mathrm{~kg}$. Drying Time: About $2 \mathrm{~kg}$ of coke was charged into the drying oven, heated at $110^{\circ} \mathrm{C}$, and scaled every $30 \mathrm{~min}$. As the result, 2.5 to $3 \mathrm{hr}$ was proved to suffice, and the required drying time was set at $3 \mathrm{hr}$. Grain Size: As the blast furnace coke had a variety of sizes although screened, sizes $100 \mathrm{~mm}$ and $15 \mathrm{~mm}$ were selected and compared after drying for $3 \mathrm{hr}$ at $110^{\circ} \mathrm{C}$, but no difference was found between the two.

(4) On-line Tests

On-line tests were carried out with an insertion type detector installed on the hopper scale of the Hirohata No. 3 blast furnace. The detector must be installed at a position which is near a place permitting easy sampling and which offers greater space than the effective volume mentioned above. The coke fed out from the ore bin is run through a vibration screen, sent to the hopper scale on a velt conveyer, and charged into the skip after being weighed. The hopper scale receives about $3.8 \mathrm{t}\left(8 \mathrm{~m}^{3}\right)$ at a time, which is held at rest for about 3 to $5 \mathrm{~min}$, although the length of time varies according to the operating condition of the skip. The coke amount entering the hopper scale was almost constant, hence the effective volume did not change at the time of measuring the moisture.

For sampling position it is ideal to collect samples near the detector, but because the hopper exit side is connected to the skip, sampling was carried out over the entry side belt conveyer.

While checking the indications of the moisture gauge, sampling was carried out three times until the output indicated the constant value, in other words from the moment coke began to enter the hopper till it exceeded the effective volume.

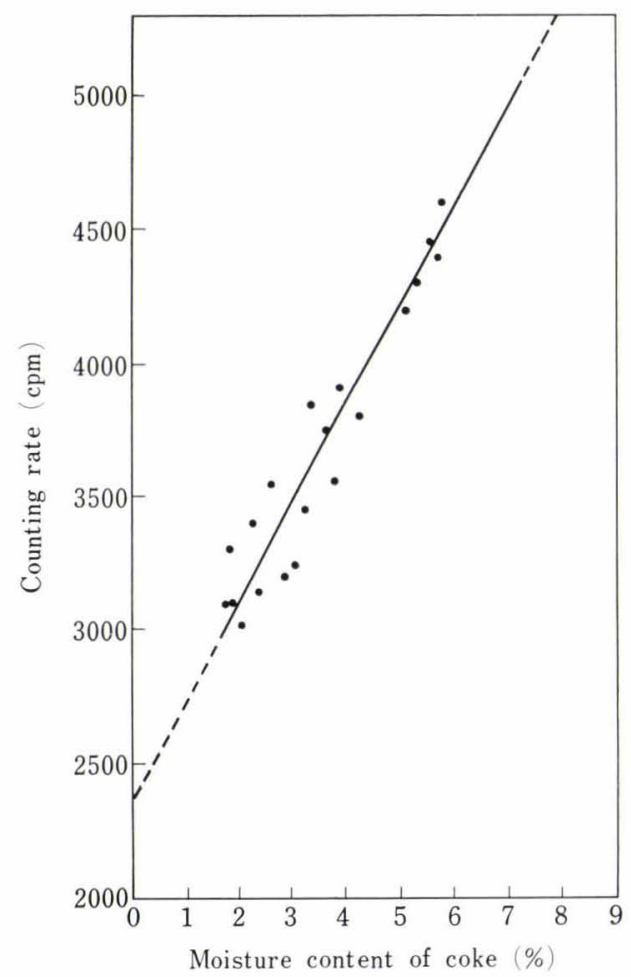

Fig. 12. Results of moisture measurement (on line test)
The relation between coke moisture content and gauge output is given in Fig. 12.

The results showed a relatively favorable linear relation between the two. Moisture measurement seems possible by means of the neutron moisture gauge. Although immediate scale correction is difficult because of the time lag involved in the measurement moisture correction, delayed one hopper movement, is possible, as the hopper scale becomes vacant each time. The detector was used for an extended period of time, but developed no instrumental variation and worked satisfactorily. However, as wear of the protective pipe presents a problem, the surface type detector is suitable for on-line operations.

\section{On-line Application of Neutron Moisture Gauge}

\section{Moisture Measurement at Blast Furnace}

The coke is thrown into the hopper scale on a batch basis by the conveyer in accordance with the other raw material charging, after having been storaged in the coke bin for some time. It is weighed at the hopper scale before being transferred to the skip and charged into the blast furnace. This system is given in Fig. 13.

To measure the moisture content of the coke, and thereby to correct the coke charge, the neutron moisture gauge probe is installed on the hopper scale to measure the coke moisture in the hopper. The probe is available in two types, the surface type and the insertion type, but the former was adopted, considering that the latter encounters great shock at the time of coke throwing in and suffers great wear of its probe protective pipe and that replacement of the worn protective pipe is difficult during continuous operation.

The coke moisture is detected by the detector probe, and the signals are recorded, while, at the same time, the value indicated by the feed setter of the scale is changed to values corresponding to the moisture content through controller and rate-meter. Thus, the quantity of coke charged can be automatically corrected in accordance with the moisture content, but with one hopper time lag. This set-up is shown in Fig. 14.

The measured moisture content is used to correct

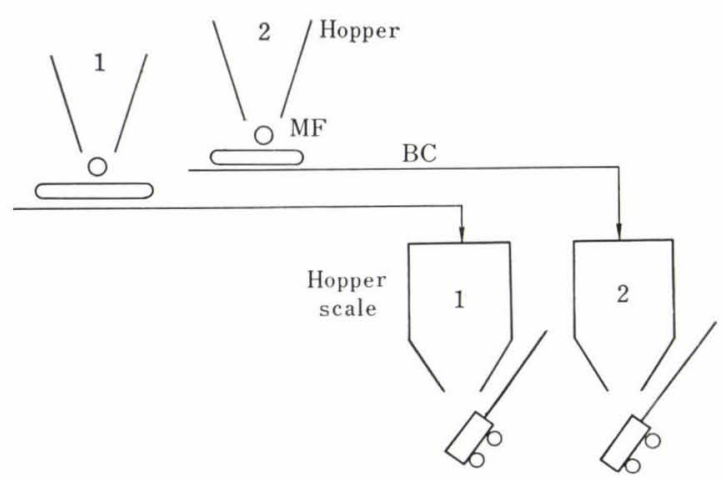

Fig. 13. Flow diagram 


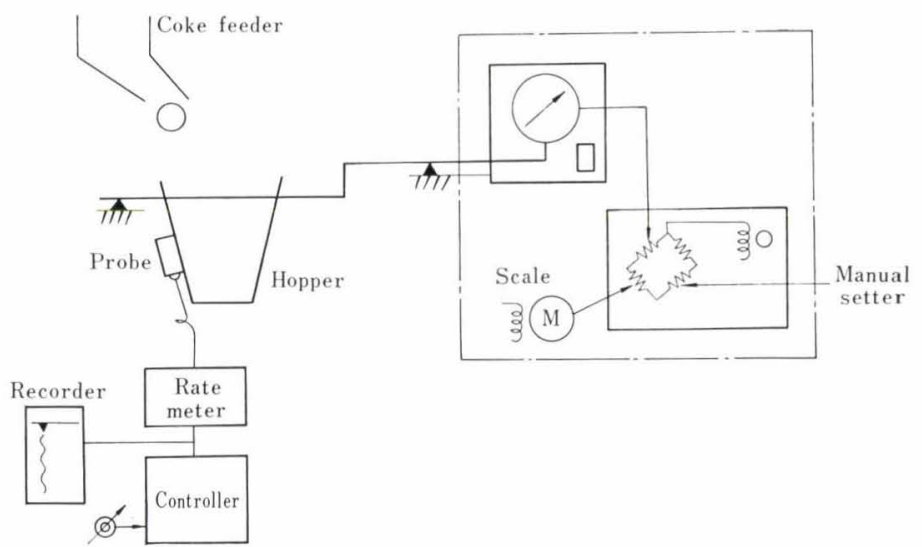

Fig. 14.

Block diagram of neutron moisture gauge

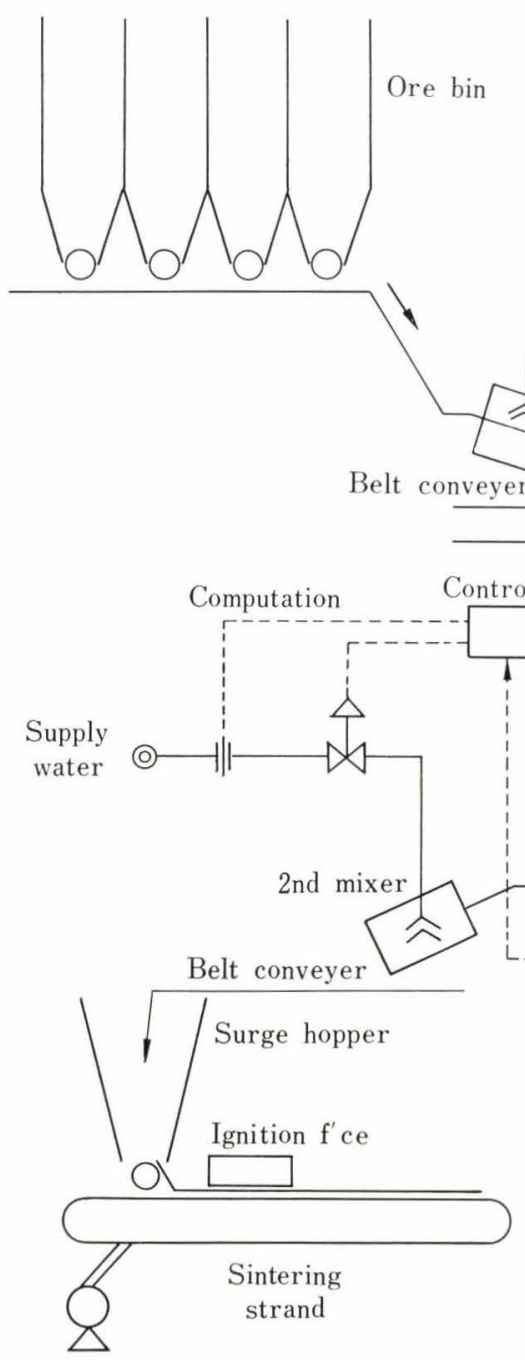

Fig. 15.

Flow diagram of sinter plant and block diagram of moisture control

the next charge, because the coke moisture content does not vary in short time. This schedule is illustrated in Fig. 15. Because there are two sets of hopper and relevant scales installed, it is necessary to install the detector probe on each hopper. It sometimes occurs that directly conveyed coke and yard stored coke are used separately for the two hoppers, or that the two types of coke are used alternately to fill the same hopper.

The approximate specifications of the moisture gauge installed at the works are as follows :

i) Moisture gauge: Am-Be $300 \mathrm{mCi}$, using $\mathrm{BF}_{3}$ proportional counter ; time constant, $30 \mathrm{sec}$; scale 0 to $15 \%$ of $\mathrm{H}_{2} \mathrm{O}$.

ii) Control panel: Bulk density and steel plate thickness correcting type, with manual moisture setter.

iii) Measurement corrector: Bridge system measured-value automatic-setting type.

iv) Scale: Hopper measuring system, stroke level 
type; weighing capacity, $5 \mathrm{t}$; minimum scale, $5 \mathrm{~kg}$.

\section{Moisture Measurement at the Sintering Plant}

The raw material for the D.L. type sintering machine is prepared by mixing various raw materials. In this system, as schematically illustrated in Fig. 15, the individual raw materials from the respectively classified ore bins are mixed in the first mixer with addition of moisture and sent to the relay hopper. Here the moisture of the raw mixture is measured and the proper amount of water is added by the automatic water addition control device to the raw mixture fed out from the relay hopper and sent to the second mixer. The moisture of raw mixture sent to the sintering machine is controlled to a proper value.

In this process, the insertion type moisture detector probe is used to more correctly measure the moisture content of the raw mixture. The system is composed of the moisture gauge probe, rate meter, moisture controller, and water addition controller. Its main specifications may be cited as follows:

i) Neutron moisture gauge: Am-Be, $300 \mathrm{mCi}$; uses $\mathrm{BF}_{3}$ proportional counter; time constant, 30 and 60 sec; scales, 0 to $8 \%$ of $\mathrm{H}_{2} \mathrm{O}$; uses ductile iron for the probe protective pipe.

ii) Moisture controller: Electronic PID adjustment ; built-in operational moisture mechanism ; with delay compensator for junction time adjustment.

iii) Water addition controller: Electronic PID adjustment; scale, 0 to $20 \mathrm{t} / \mathrm{hr}$; with automatic safety device for conveyer stopping.

\section{The Study of Moisture Measurement and Control System}

The following specific points have been studied along with the moisture measurement and automatic controlling during sintering operation.

\section{Controlling System}

Two systems of moisture controlling may be considered: (1) feed-back system, in which the raw material moisture in the surge hopper is measured and fed back for controlling at the second mixer; (2) feed-forward system, in which the raw material moisture in the relay hopper is measured and fed forward for controlling at the second mixer.

In the case of system (1), the controlling system involves a fairly great delay and moreover the delay time varies with the given operating conditions. To solve these shortcomings, a sampling control system is conceivable, but this involves the danger of mutually interfering with other control systems.

In the case of system (2), as compared with system (1), errors of the relay hopper, moisture adding device, etc., will be added to those of the moisture gauge. Moreover, dynamics errors will arise, caused by the deviation of the moisture adding device from the position of moisture measurement and the position of relay hopper feed measurement.

As mentioned above the two methods have advantages and disadvantages, and therefore it is desirable to combine both. System (2) was adopted for the following reasons: namely, provision would be devised to meet the dynamic errors ; there is no uncertainty about controllability, and so on. The apparent defects, in the meantime, were to be removed as much as possible.

\section{Probe Position}

It is desirable to insert the probe as nearly as possible at the center of the hopper for the reasons that representative value of raw material moisture can be better measured and that the raw material fluidity around the hopper is rather poor. There are two methods of probe insertion, that is, inserting it vertically to the hopper and inserting it horizontally. In the present work, the probe was installed horizontally for ease of fixing or replacing the probe protective pipe. It is desirable to install the probe at the lower part of the hopper for little control delay and correct moisture measurement. However, the probe has been installed at the position shown in Fig. 16, because of such problems as wear of the protective pipe and hanging of the raw material.

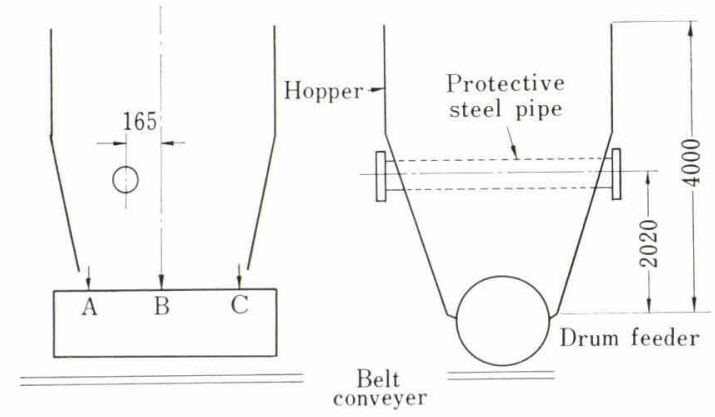

Fig. 16. Setting place of protective steel pipe in relay hopper

\section{Sticking of Raw Material to Protective Pipe}

When the protective pipe is used for long time, response of the probe becomes worse with time. This is because foreign substances in raw material are apt to stick and grow. (Figs. 17 and 18)

The possible remedies to cope with this situation include preliminary removal of foreign substances and cleaning. In the present work, foreign substances in the raw materials were removed by a lozenge-section beam over the protective pipe above the effective measurable range $(\mathrm{R}=300 \mathrm{~mm})$ of the probe. As a result, the above-mentioned phenomena decreased markedly, and the cleaning frequency of the lozengesection beam became less than ever before.

\section{Moisture Evaporation During Transfer of Raw Material}

Moisture evaporation is not desirable for precise

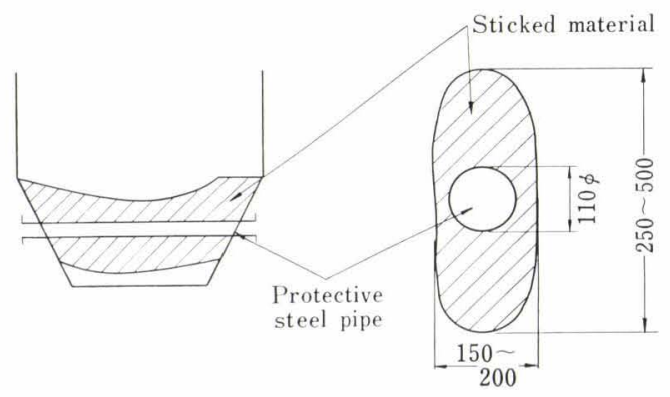

Fig. 17. Sticked state of material on the protective steel pipe 


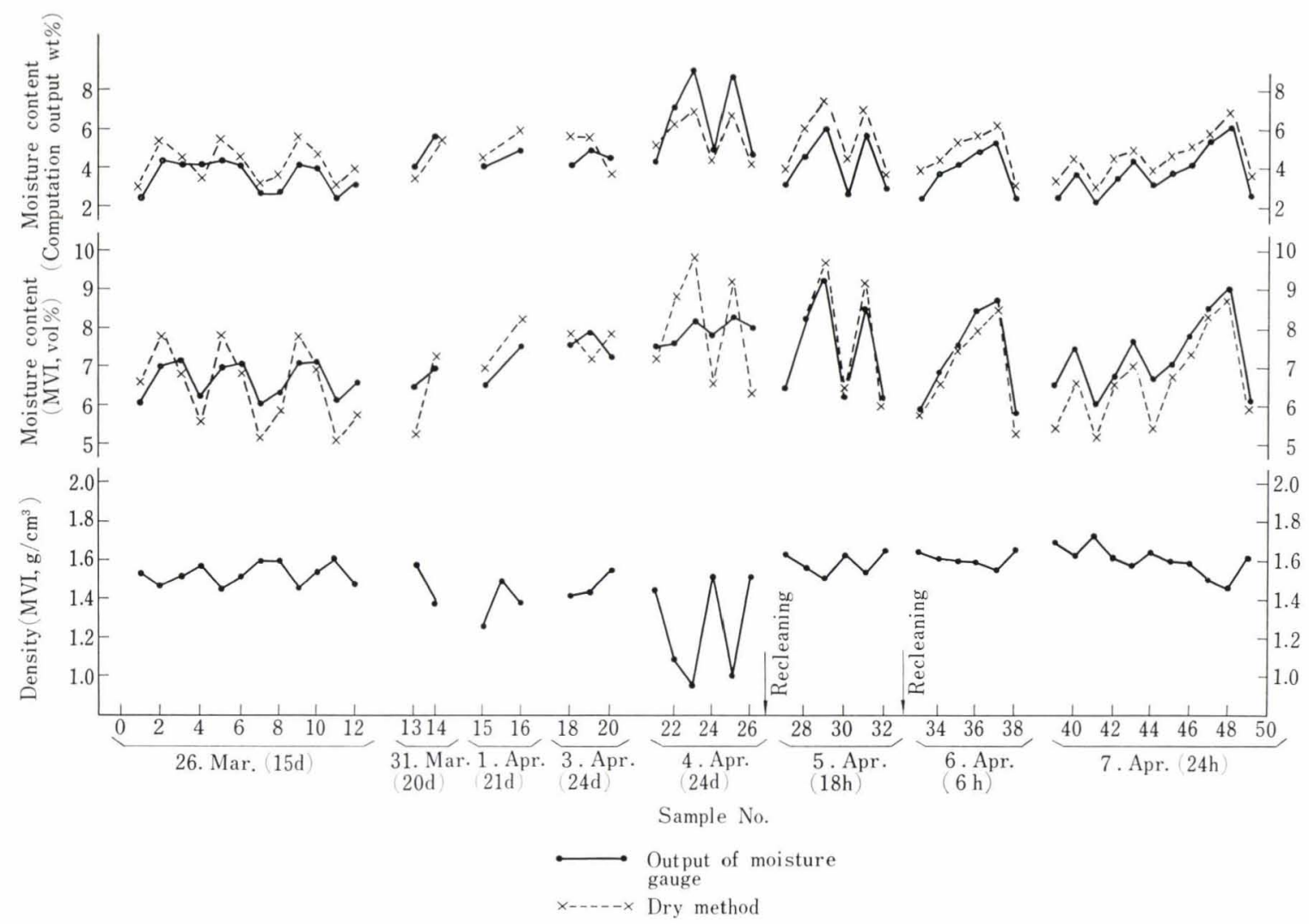

Fig. 18 Step response.

Figures in brackets indicate the duration of time after the protective steel pipe has been cleaned.

controlling, while the raw material fed out from the relay hopper proceeds to the second mixer and while it proceeds from the second mixer to the sintering machine. However, the evaporation rate was measured to be 0.1 to $0.2 \%$, which could be ignored from the control viewpoint.

\section{Preparation of Calibration Curve}

For the relation between moisture gauge output and raw materials moisture content, calibration curves must be prepared by the absolute drying method and the gauge must be adjusted accordingly. For this purpose, it is necessary to sample the raw materials of various moisture values, and determine the relation between the moisture values by the moisture gauge and by the drying method. The followings are the items that should be determined in advance in this connection :

(1) Number of moisture levels,

(2) Number of plot points per each moisture level,

(3) Number of increments per each plot point,

(4) Size of each increment, and

(5) Sampling positions and methods. In the present work these have been standardized as follows:

(1) Three levels,

(2) If the number of plot points per level is represented by $n_{1}$,

$$
n_{1}=0.8 \mathrm{Ve} / \mathrm{V}(\tilde{\mu})
$$

where, $V e$ : variance of all points

$V(\tilde{\mu})$ : calibration accuracy required.
(3) If the number of increments per plot point is represented by $n_{2}$,

$$
n_{2}=K V i / V e
$$

where, $V i$ : variance of increment unit moisture values in one charge (one plot)

$K$ : $\operatorname{constant}(3$ to 4 , from data analysis).

(4) 2 to $3 \mathrm{~kg}$ (from past results of our Works)

(5) In the case of the blast furnace, sampling by layer is carried out immediately before the hopper scale.

In the case of the sintering machine, sampling by layer is done at the roll feeder of the relay hopper.

\section{Overall Accuracy}

\section{In Case of Blast Furnace}

As shown in Fig. 19, the overall accuracy is : $\pm 0.95 \%(1 \sigma)$ (occurrence probability, 60\%) $\pm 1.9 \%(2 \sigma)$ (occurrence probability, 100\%)

$W$, the overall accuracy of the coke amount charged into the blast furnace, may be calculated from the following equation :

$$
\begin{aligned}
\Delta W_{D}= & {\left[W \pm\left(\Delta W_{1}+\Delta W_{2}\right)\right] } \\
& {[1-(h \pm \Delta h)]-W(1-h) } \\
\therefore \Delta W_{D}= & {\left[\Delta W_{1}^{2}+\Delta W_{2}^{2}+\left(\Delta W_{1}+\Delta W_{2}\right)^{2} h^{2}\right.} \\
& \left.+(\Delta h W)^{2}\right]^{1 / 2}
\end{aligned}
$$

where,

$\begin{array}{rll}W: & \text { desired charge, wet basis } & \text { (standard, } 4 \text { to } 5 \mathrm{t} \text { ) } \\ \Delta W_{1}: & \text { scale error } & \text { (standard, } 5 \mathrm{~kg}) \\ \Delta W_{2}: & \text { inflow error } & \text { (standard, } 10 \mathrm{~kg} \text { ) } \\ h: & \text { moisture value } & \text { (standard, } 5 \% \text { ) } \\ \Delta h: & \text { gauge error } & (\text { standard, } 1 \%) .\end{array}$




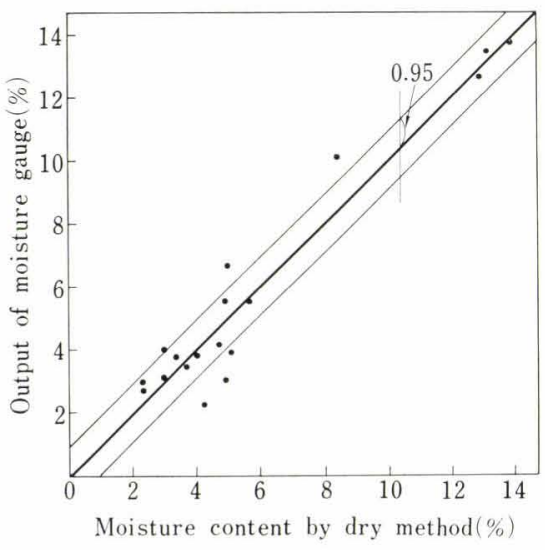

Fig. 19. Calibration curve for the coke moisture meter

In other words, it may be presumed that the coke is being controlled at about

$$
\Delta W_{D} \doteqdot 50 \mathrm{~kg} .
$$

\section{In Case of Sintering}

Various preliminary tests have revealed that control of the stuck material would make moisture control possible. The test results, as given in Figs. 20 and 21, indicate :

Total loop error of control system $0.34(1 \sigma)$

(Breakdown)

Gauge error

$0.28(1 \sigma)$

Control error

$0.19(1 \sigma)$

These tests which were carried out under actual working conditions, included at least the external disturbance that might commonly occur.

In order to study the influence of external disturbances on the total loop error of the control system, the

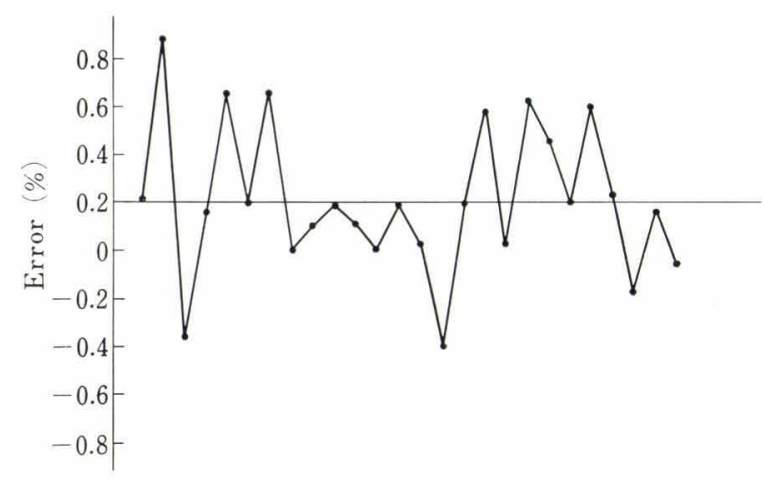

Fig. 20. $\overline{\mathrm{X}}$ control chart of the error of moisture gauge

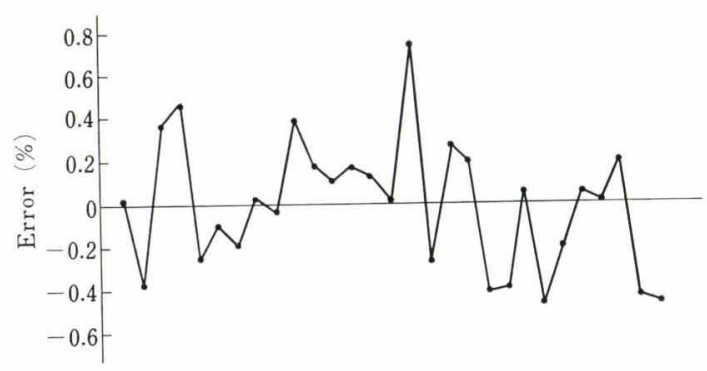

Fig. 21. $\overline{\mathrm{X}}$ control chart of the error of moisture content
Table 2. Variance analysis

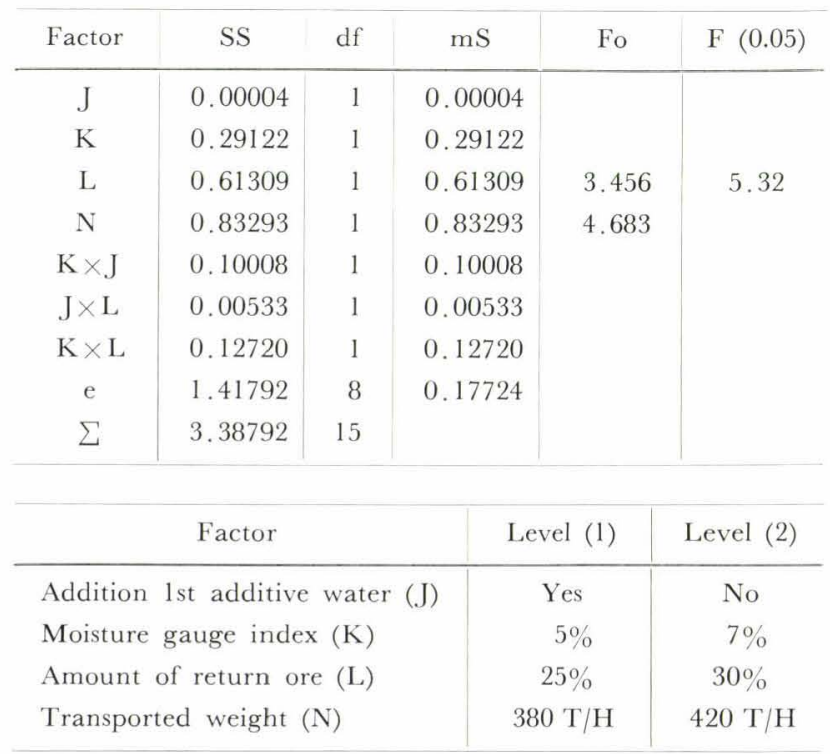

disturbance factors were plotted on an orthogonal table to quantitatively determine the control result error and its factors. The results given in Table 2 indicate the total loop errors of the control system to be somewhat greater than before, $\sigma$ standing at about 0.42 . This seems to be due to the fact that the disturbances entering the system were greater than the ordinary working condition of it.

None of the disturbance factors was separately quantified, because the factors are mutually related in complicated way. In the final analysis, the overall accuracy of the moisture controlling system is estimated at about $0.4 \%(1 \sigma)$.

\section{Error Factors}

Various errors of moisture measurement by the neutron moisture gauge may be estimated.

\section{Measuring Instrument Errors}

The errors inherent in measuring equipment include the errors in indicating recorder and detector, and the essential errors that arise from radioactive disintegration. The total error is $\pm 0.5 \%(2 \sigma)$ as measured in static state, although it somewhat varies with the type of probe. In dynamic state, the accuracy will somewhat decline owing to disturbance of the neutron path.

\section{Errors due to Segregation of Moisture Distribution in the Hopper}

The raw material distribution in the hopper changes due to viscosity, hanging, sticking, staying, dirt sticking, etc. The moisture measured by the neutron moisture gauge is not a mere mean moisture in the effective volume but a mean moisture weighed by the place. Segregation of the moisture distribution near the probe therefore becomes a major error factor. For this reason, errors can be said to depend on where the probe is installed. Quantitative determination of these errors is difficult with the poor reproducibility, but the results of an investigation in the case of sintering are given in Table 3 . These values were obtained from measurement of the moisture distribution at the 
Table 3. Variance of moisture content of material in surge hopper

\begin{tabular}{c|c|c} 
& A. B. & A. C. \\
\hline \begin{tabular}{c|c} 
Difference \\
Variance \\
to
\end{tabular} & $\mathrm{A}-\mathrm{B}=-0.09 \%$ & $\mathrm{~A}-\mathrm{C}=-0.07 \%$ \\
$\mathrm{~V}$ & 2.8 & $\mathrm{~V}_{\mathrm{AC}}=0.06 \%$ \\
$\mathrm{t}$ & \multicolumn{2}{|c}{$2.2(5 \%)$} \\
\hline
\end{tabular}

positions A, B, and $\mathrm{C}$ as shown in Fig. 15, since the direct measurement of the raw material moisture distributed on the plane of the probe insertion part was difficult.

These results suggest that the errors are very small although somewhat different among themselves. In the case of blast furnace, errors may be estimated, from the overall accuracy, at 0.2 to $0.3 \%$, although it is not that only these factors were particularly investigated.

Errors due to Variance of Bulk Density

The neutron moisture gauge, from measurement principle, gives the volume moisture content. Therefore, even with the same weight moisture content, the gauge output is different if the samples differ in bulk density. For this reason, a density gauge may be used for the density correction.

Variation of the hopper level can be controlled to a fairly negligible error only if attention be paid to the shaping of the top level of the raw material charged.

In case of the blast furnace, though a density gauge is not installed, errors of this sort will be $0.5 \%(1 \sigma)$ maximum.

\section{Errors due to the Influence of Special Elements}

If the raw material contains neutron-absorbing elements (boron, chlorine, iron, etc.), its moisture content would apparently decline.

An one per cent change of iron content in the sinter raw material means a change of about $0.05 \%$ in moisture content, but in practical operations iron content does not widely fluctuate in a short period, and so it can be corrected by means of the calibration curve. In the case of blast furnace coke, the harmful elements contained can be ignored, for they are small in amount.

Besides these special elements, attention must be paid to the possible presence of crystallized water in the raw material, for it absorbs neutron and therefore is apt to result in errors.

\section{Calibration Gurve Errors}

Accuracy of the drying method comes into question, since the preparation of calibration curve is based on moisture contents determined by the drying method.

The standard counter scale used for the drying method is of $10 \mathrm{~kg} / 5 \mathrm{~g}$ capacity range. Meanwhile the number of samples used for the preparation of calibration curves has been statistically set as already stated. Therefore, $1 / 2$ to $1 / 3$ of the overall accuracy is taken as a general standard.

\section{Errors due to Variation of Effective Volume}

These are mainly owing to variation of the hopper level, and will pose no problem if the probe position is fully studied.

\section{Errors due to Wear of Protective Pipe or Hopper Plate}

Wear of the protective pipe comes into question when the insertion type probe is used, and wear of the hopper plate when the surface type probe is used.

Figure 22 shows the influence of hopper plate thickness when the moisture content of coke is being measured.

Table 4 shows the condition of wear in the protective pipe (material: ductile cast iron) in the relay hopper. Because it is difficult to measure the amount of wear during operation, a bar of the same material such as shown in Fig. 23 was inserted into the blast furnace coke hopper for periodic measurement and correction of the wear amount. In the case of sintering, the correction amount and replacement period of the protective pipe were determined with reference to

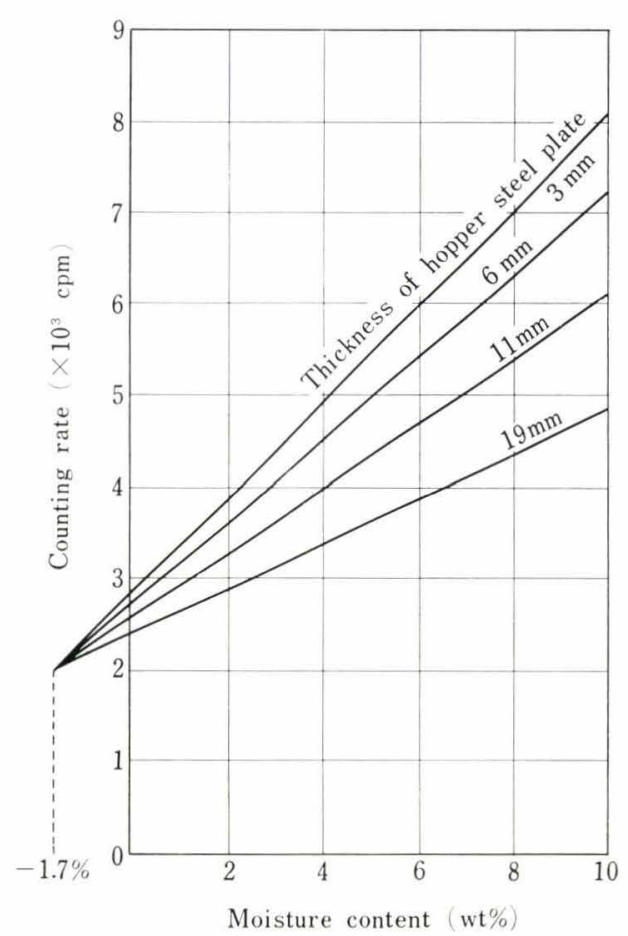

Fig. 22. Calibration curves for the coke moisture meter

Table 4. Wear of protective steel pipe

\begin{tabular}{c|c|c|c|}
\hline $\begin{array}{c}\text { Time } \\
\text { after } \\
\text { setting }\end{array}$ & Three & Six \\
$\begin{array}{c}\text { Measur- } \\
\text { ing } \\
\text { point }\end{array}$ & months & months \\
\hline $\mathrm{a}$ & $0.64^{\mathrm{mm}}$ & $0.65^{\mathrm{mm}}$ \\
$\mathrm{b}$ & 0.97 & 1.55 \\
$\mathrm{c}$ & 1.19 & 2.11 \\
$\mathrm{~d}$ & 0.46 & 1.37 \\
$\mathrm{e}$ & 1.38 & 2.61 \\
$\mathrm{f}$ & 0.45 & 1.45 \\
\hline
\end{tabular}




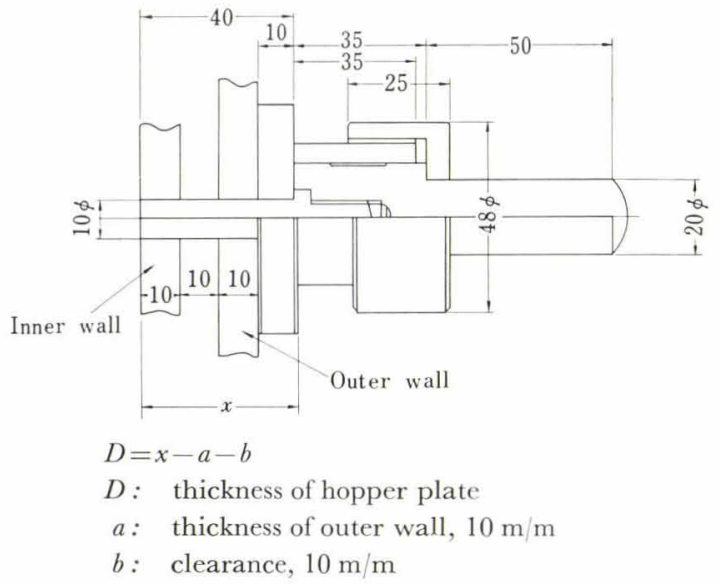

Fig. 23. Deference piece used for the measurement of wear of hopper plate

the experimental values of Table 4. This method has made it possible to safely ignore the errors.

\section{Errors due to Volatile Matter}

In the case of blast furnace coke, the content of $\mathrm{H}_{2}$ and $\mathrm{H}_{2} \mathrm{O}$ in the coke volatile matter is about 0.1 to $0.2 \%$, its errors being about $0.2 \%(\sigma)$ at most.

\section{Maintenance}

\section{Check Period}

Preservation of accuracy requires the following maintenance steps to be taken in addition to having complete equipment of instruments :

i) Calibration by moisture gauge calibrator (once a month)

ii) Rate meter calibration by built-in oscillator (once a month)

iii) Wear correction of the protective pipe and or the hopper plate (once a month)

iv) Confirmation by sampling (once a month)

v) Cleaning the protective pipe (DL) (once in 3 weeks)

vi) Replacing the protective pipe (BF)

$400 \mathrm{t} / \mathrm{h}$ pitch - once in about 10 months

$700 \mathrm{t} / \mathrm{h}$ pitch-once in about 6 months

\section{Conclusion}

(1) As a method of moisture control of blast furnace coke and sinter raw material, the technique of con- tinuous measurement and control by means of the neutron moisture gauge has been developed. It has become possible to substitute it for the conventional procedure of moisture control depending upon man's intuitive judgement or upon the drying method based on sampling.

(2) Moisture measurement of the blast furnace coke is possible with a detection accuracy of $\pm 0.95 \%$ $(1 \sigma)$, whereas its coke control is possible per charge of about $50 \mathrm{~kg}$. The question for the future is to explicate such factors as variation of moisture distribution in the hopper, variation of bulk density, etc., and thus to elevate the overall accuracy.

Practicable solutions to the variation of moisture distribution in the hopper may include calculation of the arithmetical mean and the weighted mean for the moisture values of several changes and installation of more than one probe to be averaged.

(3) The overall accuracy of moisture measurement in respect to sintering rates at $\pm 0.28 \%(1 \sigma)$, and with moisture control the accuracy was about $\pm 0.4 \%(1 \sigma)$.

For further increase of sintering productivity by means of moisture control, it is necessary to determine the optimum moisture content according to proportions of individual sinter raw materials. For this purpose, it is necessary to study the relationship that must exist between the moisture content of the material with the mixture proportion and or with the measured values of permeability, or the like, in the sintering process.

(4) For the moisture gauge itself, it is desirable that moisture contents of many levels can be calibrated by a simple method.

(5) Possible future applications in the steel industry may include moisture measurement of iron ore, moisture measurement of various raw materials on belt conveyers, and the like. But for the present, it will be necessary to solve the maintenance problems to increase sintering productivity and to stabilize blast furnace condition.

\section{Acknowledgements}

The present authors express their profound thanks to all the people concerned of the iron making department of Works and of the Tokyo Shibaura Denki and Kubota Tekko, who have extended cooperation to the present research and development program involving practical application of the neutron moisture gauge. 